\title{
Stochastic Interest Rate Approach of Pricing Participating Life Insurance Policies with Embedded Surrender Option
}

\author{
Mustapha Abdul-Rahaman ${ }^{1,}$, , Francis Oduro ${ }^{1}$, Al-Hassan Issahaku ${ }^{2}$ \\ ${ }^{1}$ Department of Mathematics, Kwame Nkrumah University of Science and Technology, Kumasi, Ghana \\ ${ }^{2}$ Department of Informatics, Regent University College of Science and Technology, Accra, Ghana \\ Email address: \\ armustaff@gmail.com(M. Abdul-Rahaman) \\ ${ }^{*}$ Corresponding author
}

\section{To cite this article:}

Mustapha Abdul-Rahaman, Francis Oduro, Al-Hassan Issahaku. Stochastic Interest Rate Approach of Pricing Participating Life Insurance Policies with Embedded Surrender Option. American Journal of Mathematical and Computer Modelling. Vol. 3, No. 1, 2018 , pp. 10-21. doi: 10.11648/j.ajmcm.20180301.12

Received: February 15, 2018; Accepted: March 9, 2018; Published: April 8, 2018

\begin{abstract}
Life insurance contracts are priced and analysed using techniques from actuarial and modern financial mathematics, which requires that, the conditions for the risk-neutral valuation are fulfilled and that, a specified underlying security and an equivalent martingale measure must exist. This paper analysed life insurance endowment policy, paid by sequence of periodical premiums in Ghana with a guaranteed minimum return to the policyholder. Again, this paper presents two premium determination schemes for the insurance policy, the constant premium case and the periodical adjustment case in which both the benefit and the periodical premiums are annually adjusted in relation to the performance of a reference portfolio. It was realized that, with rising guaranteed interest rate, the rate of return on the reference portfolio, the premiums of the whole contract decreased both in the constant and the periodical adjustment cases whiles an increase in the participating coefficient and age of the insured led to an increase in the whole premium both in the constant and periodical adjustment cases. Also, it was revealed that, the premium of the non-surrendered bonus option is smaller in the constant premium case than in the periodical adjustment case and the premium of the bonus option in the surrendered participating policy looks cheap in the constant premium case than in the periodical adjustment case. Thus, it's about $1.03 \%$ and $6.95 \%$ respectively of the total premium for the constant and for the periodical adjustment cases.
\end{abstract}

Keywords: Stochastic Interest Rate, Surrender Option, Participating Policies, Life Insurance Policy, Periodical Premiums

\section{Introduction}

Insurance provides a medium through which contingent future losses are exchange for fixed premium payments [18]. The underlying principle for the actuarial determination of premium is that, there need to be adequate on average to cover future loses. The equivalent principle is the consequent of this rationale as a basis for pricing insurance products such that the present value of premiums equals the present value of the expected future losses. Pricing both life and non-life insurance products originates from the equivalent principle, however, its application as observed by Biener requires divergent approaches in relation to different properties of risk in different line of business [6].

In life, losses are at times inevitable. People might become ill and lose their income to pay off medical bills. Individuals or their relatives may die of illness or accidents. All these activities are subject of risk of loss from unforeseen events. To lessen these burdens, insurance companies are formed to provide products, with the common goal of pooling related risks and offering a cushion to the unforeseen incidents. In expanding the coverage of life insurance products, life insurance companies have recently begun offering complex policies with embedded options. Among them is the participating policies with interest rate guarantee and surrender possibility. Bacinello defined participating policy as a contract in which the policyholder is entitled to a share of the excess profit if the realized interest rate during the insurance period is above the assumed interest rate [1].

Grosen and Jorgensen claimed interest rate guarantees, bonus distribution systems and surrender options are common features of a standard participating life insurance 
policy issued in the United States, Europe, Japan and most developing countries of which Ghana is not left out [11]. Each of these options contributes to the insurer's liability and present a value that constitutes a potential hazard to company's solvency. Similar study by Briys and De Varenne revealed that, many life insurance companies disregard the significance of these options, thereby exposing themselves to the risk of insolvency [9].

According to Bacinello, the rules for computing premium(s) are fixed in any case, thus fair pricing is achievable by selecting the appropriate parameters that characterized the contract [1].

Contrast to a standard financial instrument such as put or call options, life insurance contracts are more complex products that incorporate features like mortality/survival, periodical premiums, guarantee interest rate and the right to surrender. With-profits life insurance policies are contracts which include an annual minimum rate of return guarantee as well as a bonus distribution schemes determined by management decisions of the insurance company. They have several features and guarantees such as bonus options, surrender possibility, interest rate guarantees which poses liability to the insurer and consequently constitute the possible risks to the company's solvency [3]. Modelling and pricing participating policy that incorporate all these factors is complex and challenging. The ideal approach is to include the important factors and at the same time keep the model tractable [16]. As argued by Briys and De Varenne, most life insurance companies neglect the significance of these factors and that exposed them to the risk of insolvency [9].

Grosen and Jorgensen examined and priced participating policy with a guarantee minimum interest rate and argued that participating policies should provide a low-risk, stable and yet competitive investment opportunities. Their model includes the option to surrender and to receive the surrender value implied by a surrender charge [11]. However, they were unable to present a closed-form formula of their bonus account owing to its path dependent nature hence the adoption of Monte Carlo Methods (MCM). Bacinello analysed life insurance participating policies with a guaranteed minimum interest rate and consider both the cases in which the contract is paid by an upfront premium at issuance, and in situations in which it is paid by a sequence of periodical premiums annually adjusted in accordance with the performance of a reference portfolio. However, her analysis did not include a surrender possibility [1]. In her latter article of fair valuation of a guaranteed life insurance participating contract embedding a surrender option, she used Cox, Ross and Rubinstein model to determine the fair value of the policy paid by an upfront single premium at inception of the contract and perform sensitivity analysis on the contractual parameters that characterized the contract. She obtained a closed-form relation that makes the contract fair under Black, Scholes and Merton framework [2].

Jorgensen studied the American-style contract with a guarantee interest rate using binomial lattice [13]. Whereas Jensen, Jorgensen and Grosen priced the embedded surrender option and the bonus policy by means of finite difference approach [12].

Participating policies with embedded surrender option have been valued within the framework of constant risk-free interest rate. Ideally, the guarantee interest rate offered by the contract is more likely to change throughout the life of the policy rather than been constant. Holders of participating policies with embedded surrender possibility might surrender their contract to take advantage of the higher yield in the financial market. Surrender options have therefore become a major concern for life insurers especially during interest rate volatility. Owing to the long maturity nature of life insurance products, if the guarantee return is not sufficiently high enough compared to other forms of investments, policy holders may terminate their existing policies early in order to go in for the higher yields offered in the capital market [5].

The idea of embedding stochastic interest rates into the modelling and pricing of life insurance policy is not new. Miltersen and Persson adopted the General Health-JarrowMerton approach in a stochastic interest rates to model the minimum guaranteed rate of return. They adapted the Vasicek and Cox-Ingersoll-Ross (CIR) short rate models to derived pricing formulae for point-to-point and cliquet style guaranteed rate of return on both stock market return process and short term interest rate process [16]. Briys and De Varenne considered continuous time valuation case to modelled life insurance liability that accounts for both interest rate risk and default risk. Their model employs the instantaneous short rate by the Ornstein Uhlenbeck (OU) and obtain a closed-form formulae of certain life insurance liability [9]. Zaglauer and Bauer determined the risk-neutral value of participating life insurance policy in a stochastic interest rate environment. They used two asset market model and considered the components of the insurance company's assets portfolio implicitly by selecting adequate volatilities and correlation between the asset process and the interest rate process. Their pricing model adapt the framework proposed by [4]. They used an OU and the CIR short rate models to model the instantaneous risk-free interest rate to determine the risk-neutral price of the participating life insurance policy [19]. Furthermore, Liao, Chang and Lin priced participating contracts introduced by Bacinello embedded with surrender possibility in a stochastic interest rate model. Their study proposed a two-dimensional CRR model capable of determining the value of the surrender option embedded in the contract [14].

The purpose of this paper is to estimate the fair-price of life insurance participating policies using a stochastic interest rate model. This will provide insight about the interaction of the distinct factors that influences the premium of life insurance contract and the risk that comes along with insurers' liabilities.

\section{Materials and Methods of Analysis}

\subsection{Source of Data}

The mortality data for this paper was extracted from 2008 Society of Actuaries (SOA) life table. 


\subsection{Methods of Data Analysis}

This paper fixed the term to maturity $\mathrm{T}=10$, initial benefit $b_{1}=1000, N=250$ and $g_{t}=24.6 \%$ as guaranteed interest which was the bank of Ghana Treasury bill rate. Furthermore, a minimum of $\eta=50 \%$ as a participation level on book value earnings was credited to the policy's reserve and $i_{g}=26 \%$ as the spot rate of the zero-coupon bond. The choice of $N$ was informed by a daily change in the unit price of the relative reference portfolio since there are about 250 trading days in a year.

\subsubsection{The Policy Premium and the Reserve}

Consider a standard endowment participating life insurance policy issued at time $(t=0)$ and matures at time $(t=T)$. Under the policy arrangement, the beneficiary receive a specified amount of money if the insured dies within the contractual period or survive the maturity date. Assumed in the event of death during the $t^{\text {th }}$ contract year $(t=1.2, \ldots, T-1)$ benefit is paid at the end of the year of death otherwise paid at maturity $T$. Again, if $x$ represents the entry age of the insured at time $(t=0), b_{1}$ as the initial amount insured, payable if death occurs within the first year of the policy and $b_{t}$ as the benefit due at time $t(t=$ $2,3, \ldots, T)$. If the policy is paid by a series of periodical premiums due at the beginning of each policy year if the insured is still alive. The initial premium $P_{o}$, paid at the time of issuance of the contract is given by;

$$
P_{o}=b_{1} P_{x: \overline{T \mid}}=b_{1} \frac{A_{x: T \mid}}{\ddot{a}_{x: T \mid}}=b_{1} \frac{\sum_{t=1}^{T-1}(1+i)^{-t}{ }_{t-1 / 1} q_{x}+(1+i)^{-T}{ }_{T-1} p_{x}}{\sum_{t=0}^{T-1}(1+i)^{-t}{ }_{t} P_{x}}
$$

Where $i>0$, is the annual (compounded) technical interest rate, ${ }_{t-1 / 1} q_{x}$ denotes the probability that the insured dies within the $t^{t h}$ policy year (between times $t-1$ and $t$ ) and ${ }_{t} p_{x}$ is the probability that the insured survives to time $t$. The probabilities introduced are dependent on the age, $x$ of the insured and are usually extracted from a suitable risk-neutral mortality table implied on the technical interest rate. From equation (1), the expected value of the initial benefit $b_{1}$, discounted from the random time of payment to time zero with the technical interest rate $\left(b_{1} A_{x: T \mid}\right)$, equals the expected value at time, 0 of the sequence of the periodical premiums $P_{0}$ discounted also with the same rate $\left(P_{0} \ddot{a}_{x: \bar{T} \mid}\right)$. Hence $P_{0}$ makes the policy fair at issuance on the grounds of first order technical bases.

The benefit reserve at time $t$, of a policy issued at age $x$, that is still in force $t$ years later is defined according to [8] as the excess actuarial present value at age $x+1$ of the future premiums including any premium payable at age $x+1$. This excess represents a liability to the insurer and are usually calculated at the end of each policy year. If $P_{0}$ is paid by an insured, the technical rate could be considered as the rate of return credited to the policy reserve at the onset of the policy year. Thus, the benefit is annually adjusted, thereby resulting the dependence of the periodical premium on the performance of the reference portfolio. However, the adjustment is done in a manner that, the policy remains "fair" on the grounds of the first order technical bases in relation to the residual contract period.

If the insured is alive and the contract is still in force, and $R_{t}^{-}\left(R_{t}^{+}\right)$as the mathematical reserve of the policy at time $t$, shortly prior to the payment of the periodical premiums $P_{t}$, and (shortly after) an adjustment respectively. Then, given $b_{t}$ and $P_{t-1}, R_{t}^{-}$is given by;

$$
\begin{gathered}
R_{t}^{-}=b_{t} A_{x+t: \overline{T-t} \mid}-P_{t-1} \ddot{a}_{x+t: \overline{T-t} \mid} \\
=b_{t}\left[\sum(1+i)_{h-1 / 1}^{-h} q_{x+t}+(1+i)^{-(T-t)}{ }_{T-t} p_{x+t}\right]-P_{t-1} \sum(1+i)^{-h}{ }_{h} p_{x+t} \quad, t=1, \ldots, T-1
\end{gathered}
$$

where ${ }_{h-1 / 1} q_{x+t}$ is the probability of the insured dying within $(t+h)^{t h}$ policy year (between $t+h-1$ and $+h$ ) conditioned on the of survivorship of the insured at time, $t$ and ${ }_{h} p_{x+t}$ is the probability that the insured is still alive at time $(t+h)$ conditioned on the same event.

\subsubsection{The Reserve, Benefit and Premium Adjustment Rates}

Following the computation of $R_{t}^{-}$from Equation (2), $R_{t}^{+}$ is immediately adjusted at a rate $\delta_{t}$ such that:

$$
R_{t}^{+}=R_{t}^{-}\left(1+\delta_{t}\right) \quad, \quad t=1,2, \ldots, T-1
$$

where $\delta_{t}$ is given by;

$$
\delta_{t}=\max \left\{\frac{\eta g_{t}-i_{g}}{1+i_{g}}, 0\right\}, t=1,2,3, \ldots, T-1
$$

where $g_{t}$ represents the rate of return on the reference portfolio during the $t^{t h}$ policy year, $\eta$ is the participating 
coefficient between 0 and 1 and $i_{g}$ is the (minimum) guaranteed interest rate. Following the adjustment of the mathematical reserve, the total return credited to the insured during the $t^{t h}$ contract year implied on the guaranteed rate riches its maximum between $i_{g}$ and $\eta g_{t}$ given by;

$$
\max \left\{i_{g}, \eta g_{t}\right\}=\left(1+i_{g}\right)\left(1+\delta_{t}\right)-1, t=1, \ldots, T-1
$$

assuming $\alpha_{t}$ and $\gamma_{t}$ are the adjustment rates of the benefit and the premium respectively. It is usual in practice that the benefit and the periodical premiums of a participating policy be adjusted in the same measure as the bonus rate $\delta_{t}$, credited to the benefit reserve. Therefore, the benefit and the periodical premiums are given by Equation (6) and (7) respectively:

$$
b_{t+1}=b_{t}\left(1+\alpha_{t}\right) \quad, \quad t=1,2, \ldots, T-1
$$

and

$$
P_{t}=P_{t-1}\left(1+\gamma_{t}\right) \quad, \quad t=1,2, \ldots, T-1
$$

With regards to the residual contract period, the policy is fairly priced on the basis of first order technical bases

$$
\begin{gathered}
R_{t}^{+}=b_{t+1} A_{x+t: \overline{T-t} \mid}-P_{t} \ddot{a}_{x+t: \overline{T-t} \mid} \quad, \quad t=1,2, \ldots, T-1 \\
\alpha_{t}=\omega_{t} \delta_{t}+\gamma_{t}\left(1-\omega_{t}\right)
\end{gathered}
$$

where $\omega_{t}=\frac{R_{t}^{-}}{b_{t} A_{x+t: \overline{T-t}}}$

\subsubsection{Identical Adjustment Rates}

This paper assumed that life insurers set the same adjustment rates $\alpha_{t}=\gamma_{t}=\delta_{t}$ for any time $\mathrm{t}$ such that the mathematical reserve, the benefit and the periodical premiums are all adjusted in the same degree [2]. For a given $b_{1}$, one can ascertain an initial premium $P_{0}$ of which the contract is fairly priced at inception given by Equation (10) and (11) respectively:

$$
\begin{gathered}
b_{t+1}=b_{t}\left(1+\delta_{t}\right) \quad, \quad t=1,2, \ldots, T-1 \\
P_{t}=P_{t-1}\left(1+\delta_{t}\right) \quad, \quad t=1,2, \ldots, T-1
\end{gathered}
$$

where $\delta_{t}$ is as defined earlier.

Iteratively, Equation (10) and (11) can be expressed as

$$
b_{t}=b_{1} \prod_{k=1}^{t-1}\left(1+\delta_{t}\right) \quad, \quad t=2,3, \ldots, T
$$

$$
P_{t}=P_{0} \prod_{k=1}^{t}\left(1+\delta_{k}\right) \quad, \quad t=1,2, \ldots, T-1
$$

\subsubsection{Constant Periodical Premiums}

In order to uphold the idea of constant periodical premiums, it is apparent to assume $\gamma_{t}=0$, so that $P_{t}$ will be constant at any given time, t. Suppose $P$ denote the constant periodical premium, analysing Equation (1), (6) and (9) imply

$$
b_{t+1}=b_{t}\left(1+\omega_{t} \delta_{t}\right)=b_{t}\left(1+\delta_{t}\right)-b_{t}\left(1-\omega_{t}\right)=b_{t}\left(1+\delta_{t}\right)-\frac{P \delta_{t}}{P_{x+t: \overline{T-t}}^{(i)}}
$$

where $P_{x+t: \overline{T-t} \mid}=\frac{A_{x+t: \overline{T-t} \mid}}{\ddot{a}_{x+t: \overline{T-t} \mid}}$

Equation (14) depicts that, the benefit adjustment rate depends on the pair $(x+t, T-t)$. However, it is prudent to assume in practice that, the adjustment rate depends only on the duration, $t$ and maturity, $T$ and not on the age of the insured [2]. Therefore, Equation (14) has to be approximated by replacing $P$ with premium obtained from Equation (1) for policies belonging to the same portfolio and this gives

$$
b_{t+1}=b_{t}\left(1+\delta_{t}\right)-b_{1} \delta_{t}\left(1-\frac{t}{T}\right)
$$

Applying a convention that, $\prod_{h=1}^{t-1}\left(1+\delta_{h}\right)=1$, Equation (14) and (15) becomes, respectively

$$
\begin{aligned}
& b_{t}=b_{1} \prod_{k=1}^{t-1}\left(1+\delta_{k}\right)-P \sum_{k=1}^{t-1}\left[\frac{\delta_{k}}{P_{x+k: T-k}} \prod_{h=k+1}^{t-1}\left(1+\delta_{h}\right)\right], \quad t=2,3, \ldots, T \\
& b_{t}=b_{1}\left\{\prod_{k=1}^{t-1}\left(1+\delta_{k}\right)-\sum_{k=1}^{t-1}\left[\delta_{k}\left(1-\frac{k}{T}\right) \prod_{h=k+1}^{t-1}\left(1+\delta_{h}\right)\right]\right\}, \quad t=2,3, \ldots, T
\end{aligned}
$$

\subsubsection{Surrender Condition}

A surrender option defined by Bacinello is an American put option that entitles the policyholder to sell back the contract to the issuer at a surrender value [2]. The inclusion of a surrender possibility in a policy implies that the insured can sell back the contract to the issuing company before maturity. Thus, policy owners have the right to early termination of their contract to receive the surrender value implied by a surrender charge. Assume that surrender decisions are made at the beginning of the policy year shortly after the declaration of the renewal benefit for the coming year, and prior to the payment of the periodical premium. If $S V_{t}$ denote the surrender value at time $t$ defined by: 


$$
S V_{t}=\left\{\begin{array}{lr}
0, & t=1,2 \\
b_{t+1} A_{x+t: \overline{T-t} \mid}, & t=3,4, \ldots, T-1,
\end{array}\right.
$$

where,

$$
A_{x+t: \overline{T-t} \mid}=\sum_{t=3}^{T-1}\left(1+i_{g}\right)^{-(h-t)}{ }_{h-1 /} q_{x+t}+\left(1+i_{g}\right)_{(T-t)}^{-(T-t)} p_{x+t}
$$

The above equation is consistent with life insurance policies sold in the Ghanaian insurance market. Thus, no benefit is paid to the policy owner unless at least three periodical premiums are collected.

\subsubsection{The Model Dynamics}

Consider a life insurance endowment participating contract with embedded surrender option, the insured at maturity receive a guarantee benefit in addition to a participation bonus in return for the periodical premiums paid. In a riskneutral world, the insurer is a subject of mortality and financial risk. Assumed independence between both risks, the price of a contingent insurance claim can be formulated as the discounted expected value in relation to the risk neutral mortality and the financial elements.

As outlined by Bernard and Lemieux, the dynamic process of a zero-coupon bond in a risk neutral world with maturity $\tau$ and a reference portfolio is given by;

$$
\frac{d B(t, \tau)}{B(t, \tau)}=r_{t} d t+\sigma_{0}(t, \tau) d Z_{1}(t)
$$

$$
\frac{d S(t)}{S(t)}=r_{t} d t+\sigma_{1} d Z(t)
$$

where $Z(t)$ and $Z_{1}(t)$ are standard Brownian motions under the risk neutral measure $Q$ and $r_{t}$ is the instantaneous riskfree interest rate. If $\rho$ denote the correlation factor between two Brownian movements such that $d Z(t) d Z_{1}(t)=\rho d t$. Now considering another Brownian motion $Z_{2}(t)$ independent from $Z_{1}(t)$ such that $d Z_{1}(t) d Z_{2}(t)=0$. Then, the Brownian motion $Z(t)$ is given by;

$$
d Z(t)=\rho d Z_{1}(t)+\sqrt{1-\rho^{2}} d Z_{2}(t)
$$

Equation (21) does not correlate with the interest rate risk from the reference portfolio risk. Therefore, the reference portfolio dynamics from Equation (20) can be rewritten as;

$$
\frac{d S(0)}{S(t)}=r_{t} d t+\sigma_{1} \rho d Z_{1}(t)+\sigma_{1} \sqrt{1-\rho^{2}} d Z_{2}(t)
$$

From Girsanov's theorem, the existence of such measure is guaranteed, therefore, $Z_{1}^{T}(t)$ defined by $d Z_{1}^{T}(t)=d Z_{1}(t)+\sigma(u, t) d u$ is a $\mathrm{Q}^{\mathrm{T}}$ Brownian motion. Furthermore, building the process, $Z_{2}^{T}$ in such a way that $Z_{1}^{T}$ and $Z_{2}^{T}$ are uncorrelated and applying Itô's formula to Equation (19) and (22), the dynamics of the reference portfolio and the zero bond under the transformed $Q^{T}$ measure are given by;

$$
\begin{gathered}
\frac{S(t)}{B(0, t)}=\frac{S(0)}{B(0, t)} \exp \left\{\begin{array}{l}
\int_{0}^{t}\left(\sigma_{1} \rho-\sigma_{0}(u, t)\right) d Z_{1}^{T}(u)+\int_{0}^{t} \sigma_{1} \sqrt{1-\rho^{2}} d Z_{2}^{T}(u) \\
-\frac{1}{2} \int_{0}^{t}\left(\left(\sigma_{1} \rho-\sigma_{0}(u, t)\right)^{2}+\sigma_{1}^{2}\left(1-\rho^{2}\right)\right) d u
\end{array}\right\} \\
B(t-1, t)=\frac{B(0, t)}{B(0, t-1)} \exp \left\{\int_{0}^{t-1}(\sigma(u, t-1)+\sigma(u, t)) d Z_{1}^{T}(u)-\frac{1}{2} \int_{0}^{t-1}\left((\sigma(u, t-1)+\sigma(u, t))^{2}\right) d u\right\}
\end{gathered}
$$

Owing to the long maturity nature of most life insurance contracts and the constraints imposed on the computational viability, we assumed $\sigma(u, t)=\sigma(t-u)$ where $\sigma$ is constant as proposed by ([14]; [17]). The dynamics of relative price, $R P(t)$ in successive years $(t-1, t)$ of the reference portfolio and the zero-coupon bond under the transformed $Q^{T}$ measure are given by;

$$
R P(t)=\frac{S(0)}{B(0, t)}=\frac{1}{B(0, t)} \exp \left\{\begin{array}{l}
\int_{t-1}^{t}\left(\sigma_{1} \rho-\sigma_{0}(t-u)\right) d Z_{1}^{T}(u)+\int_{t-1}^{t} \sigma_{1} \sqrt{1-\rho^{2}} d Z_{2}^{T}(u) \\
-\frac{1}{2} \int_{t-1}^{t}\left(\left(\sigma_{1} \rho-\sigma_{0}(t-u)\right)^{2}+\sigma_{1}^{2}\left(1-\rho^{2}\right)\right) d u
\end{array}\right\}
$$




$$
B(t-1, t)=\frac{B(0, t)}{B(0, t-1)} \exp \left\{\frac{1}{2} \sigma^{2}(t-1)+\sigma Z_{1}^{T}(t-1)\right\}
$$

\subsubsection{The Pricing Framework}

Life insurance participating policy is a typical example of a contingent claim since it is affected by both mortality and financial risks. Assuming independence between these risks and that the financial and insurance markets are perfectly competitive and free of arbitrage opportunities. Also, assuming policyholders are rational and non-satiated, and to share the same information. As a result, surrender decision can only be made following the comparison of the surrender value and the continuation value, such that policyholder's surrender their contract, if and only if, the surrender value is more than the continuation value otherwise keeps the policy until the end of the coming year.

The financial risk that affects the policy under study comes from the stochastic evolution of the rates of return on the reference portfolio and the zero-coupon bond. In such instance, assume the reference portfolio is well diversified and split into units such that any yield realized is immediately reinvested and shared among all units. Thus, the reinvested yield only affects the unit price and not the total number of units involve when a withdrawal or new investment is made. This suggest that the reference portfolio price is determined by the evolution of its relative unit price. If $R P_{\tau}$ denote this price at time $(\tau>0)$, then

$$
l_{t}=\frac{R P_{t}}{R P_{t-1}}-1, t=1,2, \ldots, T-1
$$

To fairly price the participating policy with the embedded surrender option under stochastic interest rate model, we divided each contract year into $\mathrm{N}$-equal sub-period with equal length such that $\nabla=1 / N$. Following binomial evolution as proposed by [10], the relative price, $R P(t)$ at each period has two possible values, a good one denoted by $U_{R P}$ and a bad one represented by $D_{R P}$ with mathematical relations given by;

$$
\begin{aligned}
& U_{R P}=e^{r_{R P} \sqrt{\nabla}} \\
& D_{R P}=\frac{1}{U_{R P}}
\end{aligned}
$$

Under the risk-neutral measure, the probability of an event $\left\{R P_{\tau+\nabla}={ }_{u} R P_{\tau}\right\}$ conditioned on all the available relevant information at time $\tau$ is given by;

$$
P_{R P}=\frac{1-D_{R P}}{U_{R P}-D_{R P}}
$$

And the probability of the event that $\left\{R P_{\tau+\nabla}={ }_{d} R P_{\tau}\right\}$ is given by;

$$
1-P_{R P}=\frac{U_{R P}-1}{U_{R P}-D_{R P}}
$$

To avoid any arbitrage opportunity, a volatility parameter is fixed for a given drift term such that $U_{R P}>e^{r \nabla}>D_{R P}$.

This implies a strictly positive value less than one (1) for both $P_{R P}$ and $1-P_{R P}$.

Also, the above assumptions imply that $l_{t}, t=1,2, \ldots, T-1$ are i.i.d and can take $N+1$ possible values:

$$
\psi_{i}=\frac{1}{B(t-1, t)} U_{R P}^{N-i} D_{R P}^{N}-1 \quad, \quad i=0,1, \ldots, N
$$

with corresponding risk-neutral probabilities given by;

$$
P_{R P}(t)^{(i)}=\left(\begin{array}{c}
N \\
i
\end{array}\right) P_{R P}^{N-i}\left(1-P_{R P}\right)^{i} \quad, \quad i=0,1, \ldots, N
$$

Furthermore, $\delta_{t}, t=1,2, \ldots, T-1$, are i.i.d and can take $n+1$ possible values given by;

$$
\Phi_{i}=\frac{\eta \psi_{i}-i_{g}}{1+i_{g}} \quad, \quad i=0,1, \ldots, n-1
$$

with probability $P_{R P}(t)^{(i)}$ and 0 with probability

$$
1-\sum_{i=0}^{n-1} P_{R P}(t)^{(i)}
$$

\subsubsection{Fair Pricing of the Basic Contract}

The insurer's liability of the basic contract is the deterministic benefit, $b_{1}$ due at random time of death or maturity. The market value at time zero, is its expected value with respect to the risk-neutral mortality of the benefit discounted from the random time of payment to time zero implied by the risk-free interest rate, $r_{t}$ is given by;

$$
b_{1} A_{x: T \mid}=b_{1}\left[\sum_{t=0}^{T} B(0, t)_{t-1 /} q_{x}+B(0, t)_{T} p_{x}\right]
$$

Also, the sequence of constant periodical premium, $P^{B C}$ due at beginning of each policy year has its time zero market value given by;

$$
P^{B C} \ddot{a}_{x: T \mid}=P^{B C} \sum_{t=0}^{T} B(0, t){ }_{t} p_{x}
$$

Therefore, the periodical premium which equal these two is given by; 


$$
P^{B C}=b_{1} \frac{A_{x: \bar{T} \mid}}{\ddot{a}_{x: \bar{T} \mid}}=b_{1} P_{x: \bar{T} \mid}
$$

\subsubsection{Fair Pricing of the Bonus Option}

Under the non-surrendered participating policy, the insurer's liability represents the stochastic benefit due at the random time of death of the insured or at maturity. The fair value of the insurer's liability is given by;

$$
\pi\left(b_{t}\right)=\sum_{t=0}^{T} B(0, t) E_{Q}\left(b_{t}\right)_{t-1 /} q_{x}+B(0, T) E_{Q}\left(b_{T}\right)_{T} p_{x}
$$

The time zero value of the sequence of periodical premiums are also determined in the same manner. The paper identified a distinction between the adjusted and the constant periodical premiums.

\section{Identical Adjustment Rate}

Assuming the benefit $b_{t}, t \geq 1$ defined by Equation (16) and exploiting the stochastic dependence of $\delta_{k}$, for $k=1,2, \ldots, T-1$, implies;

$$
\pi\left(b_{t}\right)=b_{1}[B(0, t)] \prod_{k=0}^{t-1} E_{Q}\left(1+\delta_{K}\right)
$$

Also, taking in to account the i.i.d nature of $\delta_{k}$, Equation (39) becomes

$$
\pi\left(b_{t}\right)=b_{1} B(0, t)(1+\Phi)^{t-1}
$$

where $\Phi=E_{Q}\left[\delta_{k}\right]=\sum \Phi_{i} L_{i}$

Therefore $\pi\left(b_{t}\right)$ from equation (39) is rewritten as

$$
\pi\left(b_{t}\right)=\frac{b_{1}}{1+\Phi}\left[\sum_{t=1}^{T} B(0, t)_{t-1} q_{x}+B(0, T)_{T} p_{x}\right](1+\Phi)^{t}=\frac{b_{1}}{1+\Phi} A_{x: T}(1+\Phi)^{t}
$$

The periodical premiums have the same form as the benefit since both are adjusted by the same measure. If $P_{0}^{B O}$ denote the initial premium with market value $\pi\left(P_{0}^{B O}\right)=P_{0}^{B O}$, then from Equation (37),

$$
P_{t}^{B O}=P_{0}^{B O} \prod_{k=1}^{t}\left(1+\delta_{k}\right)
$$

$$
\text { Also, } \pi\left(P_{t}^{B O}\right)=E_{Q}\left[B(0, t) P_{t}^{B O}\right]=P_{0}^{B O} B(0, t)(1+\Phi)^{t}
$$

Hence, the fair value at time zero of the sequence of periodical premiums, $P_{t}^{B O}$ is given by;

$$
\sum_{t=0}^{T-1} \pi\left(P_{t}^{B O}\right)_{t} p_{x}=P_{0} \sum_{t=0}^{T-1} B(0, t){ }_{t} p_{x}(1+\Phi)^{t}=P_{0}^{B O} \ddot{a}_{x: \bar{T} \mid}(1+\Phi)^{t}
$$

equals the fair value of the insurer's liability, if and only if:

$$
P_{0}^{B O}=\frac{b_{1} A_{x: \bar{T} \mid}(1+\Phi)^{t}}{(1+\Phi) \ddot{a}_{x: \bar{T} \mid}(1+\Phi)^{t}}=\frac{b_{1}}{1+\Phi} P_{x: \bar{T} \mid}
$$

\section{Constant Periodical Premiums}

Consider the constant periodical benefit and the i.i.d nature of $\delta_{k}$, for $k=1,2, \ldots, T-1$, the insurer's liability of the benefit is given by;

$$
\pi\left(b_{t}\right)=b_{1} B(0, t)\left[(1+\Phi)^{t-1}-\sum_{k=1}^{t-1} \Phi(1+\Phi)^{t-k-1}\left(1-\frac{k}{T}\right)\right]=b_{1}\left(1-\frac{1}{\Phi T}\right) B(0, t)+\frac{b_{1}}{\Phi T} B(0, t)-\frac{b_{1}}{T} t B(0, t)
$$

Consequently, equation (38) is rewritten as

$$
\pi\left(b_{t}\right)=b_{1}\left(1-\frac{1}{\Phi T}\right) A_{x: T \mid}+\frac{b_{1}}{\Phi T} A_{x: \bar{T} \mid}-\frac{b_{1}}{T}(I A)_{x: T \mid}
$$

where, $(I A)_{x: \bar{T} \mid}=\sum_{t=1}^{T} t B(0, t)_{t-1} q_{x}+T B(0, T)_{T} p_{x}$

If $P^{B O}$ denote the constant periodical premium due at the beginning of each policy year if the insured is alive. As it is in the basic contract, the time zero market value of the 
sequence of periodical premiums, $P^{B O}$ is given by $P^{B O} \ddot{a}_{x: \bar{T} \mid}$. Therefore, the fair premium of the non-surrendered participating policy is given by;

$$
P^{B O}=P^{B C}\left(1-\frac{1}{\Phi T}\right)+b_{1}\left[\frac{A_{x \bar{T} \mid}-\Phi(I A)_{x: \bar{T} \mid}}{\Phi T \ddot{a}_{x: \bar{T} \mid}}\right]
$$

where, $P^{B C}$ is the fair premium of the basic contract.

\subsubsection{Fair Pricing of the Whole Contract}

The insurer's liability under the whole contract is the stochastic benefit, $b_{t}$ due at the insured random time of death or at maturity, if only policy owners does not surrender their contract. Likewise, policy owner's liabilities are presented by the periodical premiums (constant or adjusted) due at the beginning of each policy year until either surrender, death of the insured or at maturity. For any given initial premium $P_{0}$, the periodical premiums $P_{t}$, the whole contract value given by the difference between the insurer's liability and that of the policy owner's liability, and the continuation value. If $C V_{t}$ and $W_{t}$ for $t=1,2, \ldots, T-1$ denotes the continuation and the whole contract values respectively at the beginning of $(t+1)^{t h}$ policy year. At any given time $t$, the benefit is $b_{t+1}$, paid at time $t+1$, if the insured dies within times, $t$ and $t+1$, else the whole policy value is $W_{t+1}$. The continuation value $C V_{t}$ at time $t$ if the insured is alive is given by:

$$
\begin{gathered}
C V_{t}=B(t, t+1)\left[q_{x+t} b_{t+1}+p_{x+t} E_{Q}\left(W_{t+1} / \mathfrak{I}_{t}\right)\right]-P_{t}, \\
t=1,2, \ldots, T-1
\end{gathered}
$$

Special case is at time $T-1$, if the contract is still in force, policy owners received $b_{T}$, at the end of the $T^{\text {th }}$ year irrespective of whether the insured died within the $T^{\text {th }}$ year or survive the contract. Hence the policy value at maturity equals $b_{T}$. Consequently, Equation (49) becomes

$$
C V_{T-1}=b_{T} B(T-1, T)-P_{T-1}
$$

The value of the whole contract is then determined as the maximum of the continuation value and the surrender value since policy owners are rational and non-satiated, given by;

$$
W_{t}=\max \left\{C V_{t}, S V_{t}\right\}
$$

\section{Results and Discussion}

\subsection{Computational Basis}

$P_{0}$ - The initial premium paid at the time of issuance of the contract

$P^{B C}$ - The initial premium of the basic contract

$S V$ - The initial premium of the surrender option.

$P_{c}^{B O}$ - The initial premium of the non-surrendered bonus option in the constant premium case

$P_{a}^{B O}$ - The initial premium of the non-surrendered bonus option in the periodical adjustment case

$P_{a}^{W C}$ - The initial premium of the whole contract in the periodical adjustment case

$P_{c}^{W C}$ - The initial premium of the whole contract in the constant premium case

$U_{a}$ - The initial premium of the bonus option in the adjustable case given by $P_{a}^{B O}-P^{B C}$

$U_{c}$ - The initial premium of the bonus option in the constant case given by $P_{c}^{B O}-P^{B C}$

\subsection{Numerical Results}

The "fair price" of the whole contract is determined as the summation of the individual components of the policy as:

Premium of the whole contract $=$ Premium of the basic contract + Premium of non-surrendered participating option + Premium of the surrender option.

Whiles the premium of the non-surrendered participating policy is determined by:

Premium of non-surrendered participating policy $=$ Premium of the basic contract + Premium of the surrender option.

Table 1 shows the whole policy and its components versus insured age, the initial premiums of the various components that makes the policy fair at inception are:

$$
\begin{aligned}
& P_{0}=29.09, P^{B C}=27.20, \quad S V=0.32, P_{c}^{B O}=27.48, \\
& U_{c}=0.28, \quad P_{c}^{W C}=27.80, P_{a}^{B O}=28.99, \quad U_{a}=1.89, \\
& P_{a}^{W C}=29.31
\end{aligned}
$$

It was revealed that; the premium of the non-surrendered bonus option is smaller in the constant premium case than in the periodical adjustment case and the premium of the bonus option in the surrendered participating policy looks cheap in the constant premium case than in the periodical adjustment case. Thus, it's about $1.03 \%$ and $6.95 \%$ respectively of the total premium for the constant and for the periodical adjustment cases. Furthermore, the premium defined by Equation (1) is below the whole policy premium in the periodical adjustment case $\left(P_{0}<P_{a}^{W C}\right)$, and at the same time, above the premium in the constant case $\left(P_{0}>P_{c}^{W C}\right)$. The premium of the basic contract $P^{B C}$ and the premiums computed by insurer $P_{0}$ are both increasing with increasing age of the insured. These have resulted an increasing premium for the non-surrendered participating option both in the constant case and in the periodical adjustment case. The premiums for the surrender option also increases with the aged of the insured, and so does the premium for the whole contract since $P_{c}^{W C}=P_{c}^{B C}+U_{c}+S V$ in the constant case, and $P_{a}^{W C}=P_{a}^{B C}+U_{a}+S V$ in the periodical adjustment case. Also, incidence of the premium on the bonus option for the whole policy decreases from about $1.04 \%$ to $1.02 \%$ in the constant case, and about $6.14 \%$ to $6.07 \%$ in the periodical adjustment case. Likewise, the incidence of the premium of 
the surrender option on the whole policy increases from $0.60 \%$ to $2.12 \%$ in the constant case and from $0.57 \%$ to $2.02 \%$ in the periodical adjustment case. Finally, the premium, $P_{c}^{W C}$ is always smaller than the premium $P_{0}$, while
$P_{a}^{W C}$ seems to be very close to $P_{0}$ for ages 40 to 44 , and thereafter greater than the premium $P_{0}$.

Table 1. The whole policy and it's components versus insured age.

\begin{tabular}{|c|c|c|c|c|c|c|c|c|c|}
\hline \multirow[b]{2}{*}{$\mathbf{x}$} & \multirow[b]{2}{*}{$\boldsymbol{P}_{0}$} & \multirow[b]{2}{*}{$P^{B C}$} & \multirow[b]{2}{*}{$S V$} & \multicolumn{3}{|c|}{ CONSTANT PREMIUMS } & \multicolumn{3}{|c|}{ ADJUSTABLE PREMIUMS } \\
\hline & & & & $P_{c}^{B O}$ & $U_{c}$ & $P_{c}^{W C}$ & $P_{a}^{B O}$ & $U_{a}$ & $P_{a}^{W C}$ \\
\hline 40 & 26.67 & 24.76 & 0.15 & 25.02 & 0.26 & 25.17 & 26.39 & 1.63 & 26.54 \\
\hline 41 & 26.82 & 24.92 & 0.16 & 25.18 & 0.26 & 25.34 & 26.56 & 1.64 & 26.72 \\
\hline 42 & 26.99 & 25.09 & 0.17 & 25.35 & 0.26 & 25.52 & 26.74 & 1.65 & 26.91 \\
\hline 43 & 27.18 & 25.27 & 0.19 & 25.54 & 0.27 & 25.73 & 26.94 & 1.67 & 27.13 \\
\hline 44 & 27.38 & 25.48 & 0.20 & 25.75 & 0.27 & 25.95 & 27.16 & 1.68 & 27.36 \\
\hline 45 & 27.61 & 25.70 & 0.22 & 25.97 & 0.27 & 26.19 & 27.40 & 1.70 & 27.62 \\
\hline 46 & 27.85 & 25.95 & 0.23 & 26.22 & 0.27 & 26.45 & 27.66 & 1.71 & 27.89 \\
\hline 47 & 28.12 & 26.22 & 0.25 & 26.49 & 0.27 & 26.74 & 27.95 & 1.73 & 28.20 \\
\hline 48 & 28.42 & 26.52 & 0.27 & 26.79 & 0.27 & 27.06 & 28.26 & 1.74 & 28.53 \\
\hline 49 & 28.74 & 26.84 & 0.29 & 27.12 & 0.28 & 27.41 & 28.61 & 1.77 & 28.90 \\
\hline 50 & 29.09 & 27.20 & 0.32 & 27.48 & 0.28 & 27.80 & 28.99 & 1.89 & 29.31 \\
\hline 51 & 29.48 & 27.59 & 0.35 & 27.87 & 0.28 & 28.22 & 29.40 & 1.81 & 29.75 \\
\hline 52 & 29.91 & 28.01 & 0.37 & 28.30 & 0.29 & 28.67 & 29.86 & 1.85 & 30.23 \\
\hline 53 & 30.38 & 28.48 & 0.41 & 28.78 & 0.30 & 29.19 & 30.36 & 1.88 & 30.77 \\
\hline 54 & 30.89 & 28.99 & 0.44 & 29.3 & 0.31 & 29.74 & 30.90 & 1.91 & 31.34 \\
\hline 55 & 31.45 & 29.56 & 0.48 & 29.86 & 0.31 & 30.34 & 31.50 & 1.94 & 31.98 \\
\hline 56 & 32.07 & 30.17 & 0.52 & 30.49 & 0.32 & 31.01 & 32.16 & 1.99 & 32.68 \\
\hline 57 & 32.75 & 30.85 & 0.57 & 31.17 & 0.32 & 31.74 & 32.88 & 3.03 & 33.45 \\
\hline 58 & 33.49 & 31.59 & 0.62 & 31.92 & 0.33 & 32.54 & 33.67 & 2.08 & 34.29 \\
\hline 59 & 34.3 & 32.4 & 0.68 & 32.74 & 0.34 & 33.42 & 34.54 & 2.14 & 35.22 \\
\hline 60 & 35.19 & 33.29 & 0.73 & 33.64 & 0.35 & 34.37 & 35.49 & 2.20 & 36.22 \\
\hline
\end{tabular}

Figure 1 shows the influence of the insured age on premium both in the constant case and in the case in which the premium is periodically adjusted according to the performance of the reference portfolio with special references made to the premium computed by insurance companies. It shows that, the premium payable is an increase function of age.

\section{Age Versus Premium}

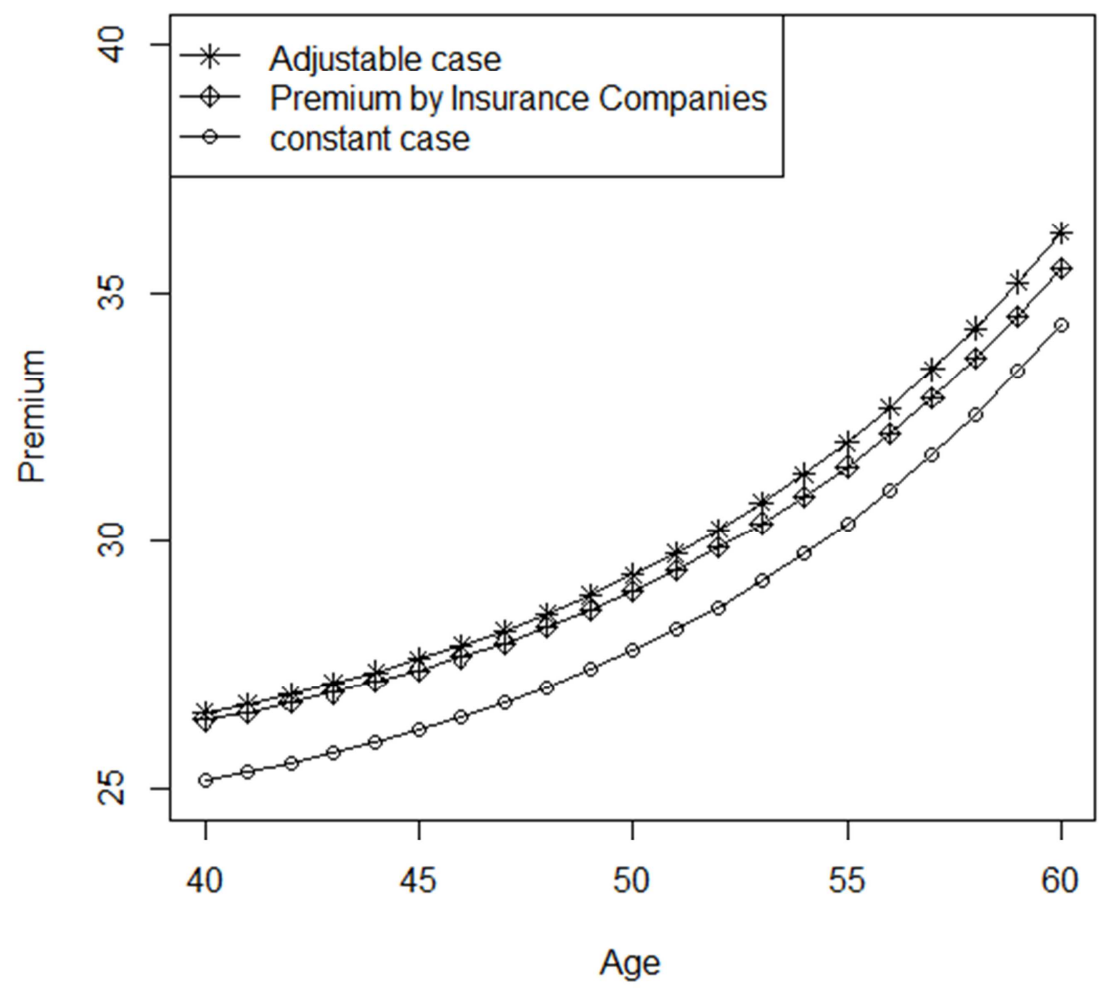

Figure 1. The influence of the insured age on premium. 


\subsection{The Policy Components and the Rate of Return}

Table 2 shows the whole premium and its components versus the rate of return. All the values presented are very sensitive to the rate of return on the reference portfolio. The premium of the basic contract is clearly decreasing with raising rate of return, and so are the premium of the non-surrendered participating policy and that of the whole policy despite an increasing trend in the premium of the walk away option. Bacinello produced the same trend on her paper on fair valuation of guarantee life insurance participating policy embedding a surrender option [2]. This is for the reason that policyholders are entitled to participate in the profit sharing of their heavily loaded premiums. The bonus option seems cheap in the constant premium case and its incidence on the whole premium decreases from $1.39 \%$ to $0.78 \%$. Whereas the premiums of the surrendered bonus option in the periodical adjustment case appears expensive with its incidence on the total premium decreasing from about $9.25 \%$ to $4.03 \%$. Finally, there exist a value of $g_{t}$ between $25 \%$ and $25.5 \%$ for which $P_{c}^{W C}=P_{0}$ in the constant premium case, and between $26 \%$ and $26.5 \%$ in the periodical adjustment case for which $P_{a}^{W C}=P_{0}$.

Table 2. The whole premium and its components versus rate of return.

\begin{tabular}{|c|c|c|c|c|c|c|c|c|}
\hline \multirow[b]{2}{*}{$g_{t}$} & \multirow[b]{2}{*}{$P^{B C}$} & \multirow[b]{2}{*}{$S V$} & \multicolumn{2}{|c|}{ CONSTANT PREMIUMS } & \multicolumn{4}{|c|}{ ADJUSTABLE PREMIUMS } \\
\hline & & & $P_{c}^{B O}$ & $U_{c}$ & $P_{c}^{W C}$ & $P_{a}^{B O}$ & $U_{\boldsymbol{a}}$ & $P_{a}^{W C}$ \\
\hline 0.20 & 36.52 & 0.27 & 37.04 & 0.52 & 37.31 & 40.27 & 3.75 & 40.54 \\
\hline 0.21 & 34.74 & 0.28 & 35.21 & 0.47 & 35.49 & 38.08 & 3.34 & 38.36 \\
\hline 0.22 & 33.05 & 0.28 & 33.48 & 0.43 & 33.76 & 36.06 & 3.01 & 36.34 \\
\hline 0.23 & 31.46 & 0.29 & 31.85 & 0.39 & 32.14 & 34.1 & 2.64 & 34.39 \\
\hline 0.24 & 29.96 & 0.30 & 30.31 & 0.35 & 30.61 & 32.29 & 2.33 & 32.59 \\
\hline 0.25 & 28.54 & 0.31 & 28.86 & 0.32 & 29.17 & 30.59 & 2.05 & 30.9 \\
\hline 0.26 & 27.20 & 0.32 & 27.48 & 0.28 & 27.8 & 28.99 & 1.79 & 29.31 \\
\hline 0.27 & 25.93 & 0.33 & 26.19 & 0.26 & 26.52 & 27.48 & 1.55 & 27.81 \\
\hline 0.28 & 24.73 & 0.33 & 24.96 & 0.23 & 25.29 & 26.07 & 1.34 & 26.4 \\
\hline 0.29 & 23.6 & 0.34 & 23.8 & 0.2 & 24.14 & 24.74 & 1.14 & 25.08 \\
\hline 0.30 & 22.54 & 0.35 & 22.72 & 0.18 & 23.07 & 23.5 & 0.96 & 23.85 \\
\hline
\end{tabular}

$P_{0}=29.09$

\subsection{The Policy Components and the Guaranteed Interest Rate}

From Table 3, the guarantee interest rate, $i_{g}$ has a little influence on the premiums of the bonus option as well as the surrender option, at least in the range of values considered. With increasing guaranteed interest rate, the premium of the bonus option also increases both in the constant and in the periodical adjustment cases. However, the premiums of the basic contract, non-surrendered participating policy as well as the premiums of the whole contract decreases with increasing guaranteed interest rate. Also, as $i_{g}$ raises, the probability that policy owners finding more profitable investment after surrendering their policy decreases. Again, there exist a level of $i_{g}$ that makes the premium computed by insurance companies equals that of the whole policy premium (between $25 \%$ and $25.5 \%$ in the constant premium case $\left(P_{c}^{W C}=P_{0}\right)$ and between $26 \%$ and $26.5 \%$ in the periodical adjustment case).

Moreover, the incidence of the surrender option on the total premium increases from $0.73 \%$ to $1.51 \%$ in the constant premium case and from $0.72 \%$ to $1.38 \%$ in the periodical adjustment case, whiles the incidence of the premium of the bonus option on the whole policy's premium increases from $0.73 \%$ to $1.38 \%$ in the constant premium case and from $1.36 \%$ to $2.57 \%$ in the periodical adjustment case.

Table 3. The whole premium and its components versus guarantee interest rate.

\begin{tabular}{|c|c|c|c|c|c|c|c|c|}
\hline \multirow[b]{2}{*}{$i_{g}$} & \multirow[b]{2}{*}{$S V$} & \multirow[b]{2}{*}{$P^{B C}$} & \multicolumn{2}{|c|}{ CONSTANT PREMIUMS } & \multicolumn{4}{|c|}{ ADJUSTABLE PREMIUMS } \\
\hline & & & $P_{c}^{B O}$ & $U_{c}$ & $P_{c}^{W C}$ & $P_{a}^{B O}$ & $U_{a}$ & $P_{a}^{W C}$ \\
\hline 0.200 & 0.27 & 36.52 & 36.79 & 0.27 & 37.06 & 37.49 & 0.97 & 37.76 \\
\hline 0.205 & 0.27 & 35.61 & 35.89 & 0.28 & 36.16 & 36.71 & 1.10 & 36.98 \\
\hline 0.210 & 0.28 & 34.74 & 35.02 & 0.28 & 35.30 & 35.95 & 1.21 & 36.23 \\
\hline 0.215 & 0.28 & 33.88 & 34.17 & 0.29 & 34.45 & 35.21 & 1.33 & 35.49 \\
\hline 0.220 & 0.28 & 33.05 & 33.34 & 0.29 & 33.62 & 34.5 & 1.45 & 34.78 \\
\hline 0.225 & 0.29 & 32.24 & 32.54 & 0.30 & 32.83 & 33.79 & 1.55 & 34.08 \\
\hline 0.230 & 0.29 & 31.46 & 31.76 & 0.30 & 32.05 & 33.10 & 1.64 & 33.39 \\
\hline 0.235 & 0.30 & 30.70 & 31.00 & 0.30 & 31.30 & 32.43 & 1.73 & 32.73 \\
\hline 0.240 & 0.30 & 29.96 & 30.26 & 0.30 & 30.56 & 31.78 & 1.82 & 32.08 \\
\hline 0.245 & 0.31 & 29.24 & 29.54 & 0.30 & 29.85 & 31.14 & 1.90 & 31.45 \\
\hline 0.250 & 0.31 & 28.54 & 28.85 & 0.31 & 29.16 & 30.51 & 1.97 & 30.82 \\
\hline 0.255 & 0.31 & 27.86 & 28.17 & 0.31 & 28.48 & 29.91 & 2.05 & 30.22 \\
\hline 0.260 & 0.32 & 27.20 & 27.51 & 0.31 & 27.83 & 29.31 & 2.11 & 29.63 \\
\hline
\end{tabular}




\begin{tabular}{|c|c|c|c|c|c|c|c|c|}
\hline \multirow[b]{2}{*}{$i_{g}$} & \multirow[b]{2}{*}{$S \boldsymbol{V}$} & \multirow[b]{2}{*}{$P^{B C}$} & \multicolumn{2}{|c|}{ CONSTANT PREMIUMS } & \multicolumn{4}{|c|}{ ADJUSTABLE PREMIUMS } \\
\hline & & & $P_{c}^{B O}$ & $U_{c}$ & $P_{c}^{W C}$ & $P_{a}^{B O}$ & $U_{a}$ & $P_{a}^{W C}$ \\
\hline 0.265 & 0.32 & 26.55 & 26.87 & 0.32 & 27.19 & 28.73 & 2.18 & 29.05 \\
\hline 0.270 & 0.33 & 25.93 & 26.24 & 0.32 & 26.57 & 28.17 & 2.24 & 28.50 \\
\hline 0.275 & 0.33 & 25.32 & 25.64 & 0.32 & 25.97 & 27.62 & 2.30 & 27.95 \\
\hline 0.280 & 0.33 & 24.73 & 25.05 & 0.32 & 25.38 & 27.08 & 2.35 & 27.41 \\
\hline 0.285 & 0.34 & 24.16 & 24.48 & 0.32 & 24.82 & 26.56 & 2.40 & 26.90 \\
\hline 0.290 & 0.34 & 23.60 & 23.92 & 0.32 & 24.26 & 26.06 & 2.46 & 26.40 \\
\hline 0.295 & 0.35 & 23.06 & 23.38 & 0.32 & 23.73 & 25.55 & 2.49 & 25.90 \\
\hline 0.300 & 0.35 & 22.53 & 22.85 & 0.32 & 23.20 & 25.06 & 2.53 & 25.41 \\
\hline
\end{tabular}

$P_{0}=29.09$

\subsection{The Policy Components and the Participating Co-efficient}

As far as the participating co-efficient is concerned, the results as reported in Table 4 revealed a very strong influence on the premiums of the surrendered participating policy as well as the bonus option, both in the constant case and in the periodical adjustment case. All the premiums are increasing, though the trend in the non-surrendered participating policy in the periodical adjustment case beats that of the constant case. The participating co-efficient has no or little influence on the premiums of the basic contract and that lives its value same for different levels of the participating co-efficient. The bonus option valued less in the constant premium case than in the periodical adjustment case, at least in the range of values considered for all the different levels of $\eta$. The incidence of the bonus option on the whole premium in the constant premium case increases from about $0.51 \%$ to $9.80 \%$ whiles from $0.94 \%$ to about $18.53 \%$ in the periodical premium case. Finally, there exist a value of $\eta$ for which the whole premium equals $P_{0}$ (between $55 \%$ and $60 \%$ in the constant premium case, and between $40 \%$ and $45 \%$ in the periodical adjustment case).

Table 4. The whole premium and its components versus $\eta$

\begin{tabular}{|c|c|c|c|c|c|c|}
\hline \multirow[b]{2}{*}{$\eta$} & \multicolumn{2}{|c|}{ CONSTANT PREMIUMS } & \multicolumn{4}{|c|}{ ADJUSTABLE PREMIUMS } \\
\hline & $P_{c}^{B O}$ & $\boldsymbol{U}_{c}$ & $P_{c}^{W C}$ & $P_{a}^{B O}$ & $U_{a}$ & $P_{a}^{W C}$ \\
\hline 0.15 & 27.34 & 0.14 & 27.66 & 27.46 & 0.26 & 27.78 \\
\hline 0.20 & 27.41 & 0.21 & 27.73 & 27.76 & 0.56 & 28.08 \\
\hline 0.25 & 27.55 & 0.35 & 27.89 & 28.06 & 0.86 & 28.38 \\
\hline 0.30 & 27.71 & 0.51 & 28.08 & 28.36 & 1.16 & 28.68 \\
\hline 0.35 & 27.90 & 0.70 & 28.22 & 28.67 & 1.47 & 28.99 \\
\hline 0.40 & 28.08 & 0.88 & 28.40 & 28.99 & 1.79 & 29.31 \\
\hline 0.45 & 28.26 & 1.06 & 28.58 & 29.32 & 2.12 & 29.64 \\
\hline 0.50 & 28.44 & 1.24 & 228.76 & 29.65 & 2.45 & 29.97 \\
\hline 0.55 & 28.62 & 1.42 & 28.94 & 29.99 & 2.79 & 30.31 \\
\hline 0.60 & 28.81 & 1.61 & 29.13 & 30.34 & 3.14 & 30.66 \\
\hline 0.65 & 29.00 & 1.80 & 29.32 & 30.7 & 3.5 & 31.02 \\
\hline 0.70 & 29.20 & 2.00 & 29.52 & 31.07 & 3.87 & 31.39 \\
\hline 0.75 & 29.40 & 2.20 & 29.72 & 31.44 & 4.24 & 31.76 \\
\hline 0.80 & 29.61 & 2.41 & 29.93 & 31.82 & 4.62 & 32.14 \\
\hline 0.85 & 29.87 & 2.67 & 30.19 & 32.32 & 5.12 & 32.64 \\
\hline 0.90 & 30.03 & 2.83 & 30.35 & 32.62 & 5.42 & 32.94 \\
\hline 0.95 & 30.25 & 3.05 & 30.57 & 33.03 & 5.83 & 33.35 \\
\hline 1.00 & 30.48 & 3.28 & 30.80 & 33.46 & 6.26 & 33.78 \\
\hline
\end{tabular}

$P_{0}=29.09, P^{B C}=27.20, S V=0.32$

\section{Conclusion}

The purpose of this paper was to estimate the fair-price of life insurance participating policy using a stochastic interest rate model. The results indicate that, for a life policy, the premium of the non-surrendered bonus option was smaller in the constant premium case, than it is, in the periodical adjustment case. In comparing the policy components and the rate of return, it was revealed that, the basic contract was decreasing with increasing rate of return and so were the premiums. The guaranteed interest rate had a little influence on the premium of the bonus option as well as the surrender option. Also, the participating co-efficient had a positive influence on the premiums of the surrendered participating policy as well as the bonus option.

\section{References}

[1] Bacinello, A. R. (2001). Fair pricing of life insurance participating policies with a minimum interest rate guaranteed. Astin Bulletin, 31(02): 275-297.

[2] Bacinello, A. R. (2003a). Fair valuation of a guaranteed life insurance participating contract embedding a surrender option. Journal of Risk and Insurance, 70(3): 461-487. 
[3] Ballotta, L., Haberman, S., \& Wang, N. (2006). Guarantees in With-Profit and Unitized With-Profit Life Insurance Contracts: Fair Valuation Problem in Presence of the Default Option. Journal of Risk and Insurance, 73(1): 97-121.

[4] Bauer, D., Kling, A., \& Russ, J. (2008). A universal pricing framework for guaranteed minimum benefits in variable annuities. Astin Bulletin, 38(02): 621-651.

[5] Bernard, C., \& Lemieux, C. (2008). Fast simulation of equitylinked life insurance contracts with a surrender option. In Proceedings of the 40th Conference on Winter Simulation (pp.444-452). Winter Simulation Conference. Retrieved from http://dl.acm.org/citation.cfm?id=1516831

[6] Biener, C. (2013). Pricing in microinsurance markets. World Development, 41:132-144.

[7] Black, F., \& Scholes, M. (1973). The pricing of options and corporate liabilities. The Journal of Political Economy, pages 637-654.

[8] Bowers, N. L., Gerber, H. U., Hickman, J. C., Jones, D. A., \& Nesbitt, C. J. (1986). Actuarial mathematics (Vol. 2). Society of Actuaries Itasca, Ill. Retrieved from http://www.sidalc.net/cgibin/wxis.exe/?IsisScript=FCEAL.xis \&method $=$ post $\&$ formato $=2 \&$ cantidad $=1 \&$ expresion $=m f n=00$ 4732

[9] Briys, E., \& De Varenne, F. (1997). On the risk of insurance liabilities: debunking some common pitfalls. Journal of Risk and Insurance, pages 673-694.

[10] Cox, J. C., Ross, S. A., \& Rubinstein, M. (1979). Option pricing: A simplified approach. Journal of Financial Economics, 7(3): 229-263.

[11] Grosen, A., \& Jorgensen, P. L. (2000). Fair valuation of life insurance liabilities: the impact of interest rate guarantees, surrender options, and bonus policies. Insurance: Mathematics and Economics, 26(1): 37-57.
[12] Jensen, B., Jorgensen, P. L., \& Grosen, A. (2001). A finite difference approach to the valuation of path dependent life insurance liabilities. The Geneva Papers on Risk and Insurance Theory, 26(1): 57-84.

[13] Jorgensen, P. L. (2001). Life Insurance Contracts with Embedded Options: Valuation, Risk Management, and Regulation. Risk Management, and Regulation (December 13, 2012). Journal of Risk Finance, 3(1): 19-30.

[14] Liao, S.-L., Chang, C.-K., \& Lin, S.-K. (2006). Fair Valuation of Participating Policies in Stochastic Interest Rate Models: Two-dimensional Cox-Ross-Rubinstein Approaches. Retrieved from http://www.aria.org/meetings/2006papers/Liao, Szu-LangChiKaiShih-Kuei.pdf

[15] Merton, R. C. (1973). Theory of rational option pricing, The Bell Journal of Economics and Management Science 4 (1): 141-183. URL: Http://www. Jstor. org/stable/3003143.

[16] Miltersen, K. R., \& Persson, S.-A. (2003). Guaranteed investment contracts: distributed and undistributed excess return. Scandinavian Actuarial Journal, 2003(4): 257-279.

[17] Nielsen, J. A., \& Sandmann, K. (1995). Equity-linked life insurance: A model with stochastic interest rates. Insurance: Mathematics and Economics, 16(3): 225-253.

[18] Wang, S. (1995). Insurance pricing and increased limits ratemaking by proportional hazards transforms. Insurance: Mathematics and Economics, 17(1): 43-54.

[19] Zaglauer, K., \& Bauer, D. (2008). Risk-neutral valuation of participating life insurance contracts in a stochastic interest rate environment. Insurance: Mathematics and Economics, 43(1): $29-40$. 